\title{
User Experience of ColdZyme Mouth Spray against Common Cold in Competitive Athletes
}

\author{
Ulf Blom, Ida Nelson \\ Enzymatica AB, Lund, Sweden \\ Email: ida.nelson@enzymatica.com
}

How to cite this paper: Blom, U. and Nelson, I. (2018) User Experience of ColdZyme Mouth Spray against Common Cold in Competitive Athletes. Open Journal of Respiratory Diseases, 8, 13-20. https://doi.org/10.4236/ojrd.2018.82002

Received: March 16, 2018

Accepted: April 6, 2018

Published: April 9, 2018

Copyright $\odot 2018$ by authors and Scientific Research Publishing Inc. This work is licensed under the Creative Commons Attribution International License (CC BY 4.0).

http://creativecommons.org/licenses/by/4.0/

(c) (i) Open Access

\begin{abstract}
ColdZyme ${ }^{\oplus}$ Mouth Spray (ColdZyme) is intended to reduce the probability of catching a cold and/or can help shorten the duration of a cold, if used at an early stage of the infection, by forming a barrier on the pharyngeal mucous membrane. The user experience of ColdZyme on naturally occurring common cold infections was evaluated in competitive athletes training professionally or on an amateur level. Thirteen athletes completed weekly electronic surveys on occurrence of common colds, cold severity and user experience over the course of 3 months. The 13 participants reported in total 15 cold incidents with an average duration of 7.4 days. The average cold severity was 31.2 on a visual-analogue scale (VAS) ranging from 0 (mildest possible cold) to 100 (worst possible cold). The overall user satisfaction with ColdZyme was high. $81 \%$ of the reported colds were experienced to be milder and/or shorter than usual. None of the participants reported "No effect". Out of the participants who reported absence of a cold in the previous week, $69 \%$ reported a positive answer to the question if ColdZyme had prevented them from catching a cold in the previous week. Conclusion: The present study evaluated prevention and alleviation of naturally occurring common cold in athletes, and demonstrated that ColdZyme may be an easy and practical way for competitive athletes to prevent or reduce infections of the common cold virus and corresponding unwanted absence from training and competition. Due to the lack of a comparator group, a placebo effect cannot be excluded.
\end{abstract}

\section{Keywords}

Common Cold, Athletes, ColdZyme ${ }^{\circledast}$, Mouth Spray

\section{Introduction}

Upper respiratory symptoms are the most common medical condition affecting 
elite athletes. Studies show that elite athletes suffer from more common colds and upper respiratory tract infections than recreational athletes [1] [2]. There is a well-established association between prolonged hard exercise and suppressed immune function [3]. The transient immune suppression after heavy exercise is thought to create an opportunity for viruses to gain a foothold, thereby increasing the risk of developing an infection [4]. According to Gleeson [5] the post-exercise immune function decrease is most pronounced when the exercise is continuous, prolonged $(>1.5 \mathrm{~h}$ ), of moderate to high intensity $(55 \%-75 \%$ of aerobic capacity) and performed without food intake. The prevention of common cold infections is therefore particularly important for athletes during prolonged periods of heavy training, in order to avoid the negative influence of a cold on performance. Repeated periods of infection are also linked to recurrent physical injuries that can be detrimental for the athlete and the team [6]. Upper respiratory tract infection, such as common cold, is one of the main reason for missed training among UK elite athletes in 30 different Olympic sports. Common cold has further been reported to be the most common medical condition affecting athletes at both the summer and winter Olympic Games [7]. According to the International Olympic Committee Consensus Statement on Load in Sport and Risk of Illness it is estimated that about $50 \%$ of all acute illness in athletes during competitions and tournaments affect the respiratory tract [6]. In conclusion, the specific conditions for elite athletes, such as hard exercise and travelling, increase susceptibility for infection by common cold viruses [2] [8].

ColdZyme $^{\oplus}$ Mouth Spray (ColdZyme) is a medical device against common cold. It is designed to deposit a viscous solution containing primarily glycerol and trypsin to the mouth/throat and thereby reducing the probability of catching a cold and to help shorten duration of a cold by forming a thin protective barrier on the oropharyngeal mucous membrane. Epithelial cell layers in oral and nasal cavities form a physical and innate immune barrier against bacteria and viruses [9]. Yet, viruses can infect the mucosal cells in this area resulting in cold symptoms. To prevent infection, the natural barrier can be strengthened by depositing a barrier to the oropharyngeal mucous membrane. In a clinical study, ColdZyme decreased the viral load significantly $(p=0.02)$ and the number of days for one episode with common cold symptoms was reduced from 6.5 to 3 days, in comparison to placebo [10].

The purpose of this post-market evaluation was to investigate the user experience of ColdZyme ${ }^{\varpi}$ Mouth Spray, when used by competitive athletes who are training professionally or on an amateur level.

\section{Methods}

ColdZyme $e^{\oplus}$ Mouth Spray (Enzymatica AB, Lund, Sweden) is a non-prescription medical device available in several European markets. The product consists of a combination of glycerol, menthol and of trypsin, which is derived from Atlantic cod. When applied to the oral mucosa, the spray is believed to reduce the ability of virus to attach to mucosal cells through a mechanical barrier created by gly- 
cerol [11] and menthol, and by the virus-deactivating capacity of cod trypsin [12]. Seventeen athletes, involved in competitive training on a professional or amateur level, were invited via e-mail to participate in a weekly electronic diary survey. They were enrolled to evaluate their use of ColdZyme after expressing an interest in the product. No other selection criteria were used and no power calculation to determine sample size was done. Two subjects never responded and another two were excluded from the analysis as they by mistake only received the survey once. The other 13 participants completed the survey. User experience of the effect of ColdZyme, number of common colds, cold severity and use of ColdZyme were reported weekly. A formal approval from the local ethics committee was not necessary for this evaluation. No background information on health status or demographics (i.e. age or gender) was collected. For calculation of mean, confidence intervals, frequencies and standard deviations, the statistical functions in Excel 2016 were used.

The evaluation took place between April and June of 2017. The participants received a weekly electronic survey for 3 months, where they retrospectively reported the common colds that they experienced during the previous week and graded the average daily severity of the cold using the Jackson rating scale [13] and a visual-analogue scale (VAS) graded from 0 (mildest possible cold) to 100 (worst possible cold). In total, 12 surveys per subject were sent out. Identifying information was replaced by a Subject ID number before closing the study and saving the final data sheets in password protected electronic formats.

Since the cold, and a weekly estimate of the average daily severity score, were reported retrospectively instead of daily, the commonly used definition of a common cold incident by Jackson et al. in 1958 [13], where a separate incident has to be preceded with at least two days of a Jackson score $<5$, could not be used. Instead, all reported days were counted as days with common cold. If $>3$ days of cold were reported the previous week, reported days the following week were counted as belonging to the same incident. The evaluation was designed to be as real-life as possible. The participants received ColdZyme for free during their participation, but did not receive any financial compensation.

\section{Results}

\subsection{Compliance}

The answer rate was above $77 \%$ throughout the evaluation period, which is higher than expected based on previous surveys published in medical journals [14]. On average 2.1 ( $95 \% \mathrm{CI} \pm 0.5$ ) doses of ColdZyme were used per day for prevention, when not having a cold, and $4.4(95 \% \mathrm{CI} \pm 0.9)$ doses of ColdZyme per day when having a cold. This dosing of ColdZyme is below the recommendations in the Instructions For Use. Recommendations are to spray one dose every second hour when believed being exposed to cold virus. To obtain shortening of the duration of a cold it is recommended to start to spray one dose every second hour as soon as possible after noticing symptoms of a cold and to 
continue until the symptoms are relieved.

\subsection{Cold Incidents, Duration and Severity}

The number and duration of colds could only be approximately determined, due to the weekly reporting where the participants were asked "How many days last week did you have a cold?" In those cases where participants reported $>3$ days with a cold for consecutive weeks, it was considered as the same cold incident. During the three months, the 13 participants reported 15 colds. Five of the 13 participants did not report any colds during the three months.

As shown in Table 1, the average duration of a cold was 7.4 (95\% CI \pm 4.8 ) days. Symptoms typically peak at $1-3$ days and last $7-10$ days, although they occasionally persist for three weeks [15]. The average cold severity was 31.2 on a visual-analogue scale, ranging from 0 (mildest possible cold) to 100 (worst possible cold). The use of VAS in common cold needs to be validated in further studies. The severity score was measured with the Jackson scale, where the participants who reported having a cold were asked to rate the severity for each individual symptom during days with a cold as absent (0), mild (1), moderate (2) or severe (3). The Jackson score is calculated as the sum of all individual symptom scores. The average Jackson score for days with a cold was 6.9 (95\% CI \pm 2.8 ). The individual symptom with the highest rating was blocked nose, followed by malaise. Fever was the symptom with the lowest rating.

Table 1. Summary of average duration and severity ratings for each subject.

\begin{tabular}{|c|c|c|c|c|c|c|c|c|c|c|c|c|c|}
\hline Subject ID & Incidents & Duration & $\begin{array}{c}\text { VAS } \\
0-100\end{array}$ & Sneezing & Rhinorrhea & $\begin{array}{c}\text { Blocked } \\
\text { Nose }\end{array}$ & $\begin{array}{l}\text { Sore } \\
\text { Throat }\end{array}$ & Cough & Headache & Malaise & Hoarseness & Fever & $\begin{array}{c}\text { Total } \\
\text { Jackson } \\
\text { Score }\end{array}$ \\
\hline 1 & 0 & & & & & & & & & & & & \\
\hline 4 & 2 & 11 & 18.8 & 0.4 & 0.2 & 1.2 & 1.0 & 0.0 & 1.0 & 0.8 & 0.0 & 0.0 & 4.6 \\
\hline 5 & 1 & 4 & 2.0 & 0.0 & 1.0 & 1.0 & 1.0 & 0.0 & 0.0 & 1.0 & 0.0 & 0.0 & 4.0 \\
\hline 6 & 0 & & & & & & & & & & & & \\
\hline 7 & 0 & & & & & & & & & & & & \\
\hline 8 & 1 & 24 & 52.5 & 0.5 & 1.0 & 1.3 & 1.3 & 2.0 & 1.5 & 1.5 & 0.8 & 0.8 & 10.5 \\
\hline 9 & 4 & 5 & 15.2 & 0.7 & 1.0 & 0.7 & 0.0 & 0.0 & 0.0 & 1.2 & 0.3 & 0.0 & 3.8 \\
\hline 10 & 2 & 2 & 35.5 & 2.0 & 1.5 & 2.0 & 0.5 & 0.5 & 1.0 & 1.5 & 1.0 & 0.0 & 10.0 \\
\hline 11 & 0 & & & & & & & & & & & & \\
\hline 12 & 1 & 7 & 22.5 & 0.5 & 0.5 & 1.5 & 0.0 & 0.0 & 0.0 & 1.0 & 0.0 & 0.0 & 3.5 \\
\hline 13 & 1 & 3 & 70.0 & 1.0 & 2.0 & 2.0 & 1.0 & 3.0 & 1.0 & 2.0 & 1.0 & 1.0 & 14.0 \\
\hline 16 & 3 & 3 & 33.0 & 0.3 & 1.0 & 1.0 & 0.3 & 1.0 & 0.0 & 0.7 & 0.3 & 0.0 & 4.7 \\
\hline 17 & 0 & & & & & & & & & & & & \\
\hline Average* & 1.2 & 7.4 & 31.2 & 0.7 & 1.0 & 1.3 & 0.6 & 0.8 & 0.6 & 1.2 & 0.4 & 0.2 & 6.9 \\
\hline $\mathrm{n}$ & 13 & 8 & 8 & 8 & 8 & 8 & 8 & 8 & 8 & 8 & 8 & 8 & 8 \\
\hline $95 \%$ CI & 0.7 & 5.1 & 15.1 & 0.4 & 0.4 & 0.3 & 0.3 & 0.8 & 0.4 & 0.3 & 0.3 & 0.3 & 2.8 \\
\hline
\end{tabular}

${ }^{\star}$ Average calculated value of participants who had a cold incident. 


\subsection{User Experience in Participants Who Experienced a Cold}

The participants were asked if they experienced any effect of ColdZyme on the reported colds. $43 \%$ of the colds were experienced as both milder and shorter than usual, $24 \%$ of the colds were reported as shorter, $14 \%$ were reported as milder and 19\% were reported as "don't know". None of the participants reported "no effect" (Figure 1).

When asked if the experienced cold had any effect on the ability to perform physical training at all, $41.7 \%$ of the participants exercised as usual, $45.8 \%$ were forced to reduce training and only $12.5 \%$ were not able to train.

\subsection{User Experience in Participants Who Did Not Experience a Cold}

When the participants who did not report any colds in the previous week were asked if they thought that ColdZyme had prevented them from catching a cold, the majority, $69 \%$ of participants, gave a positive answer (Figure 2).

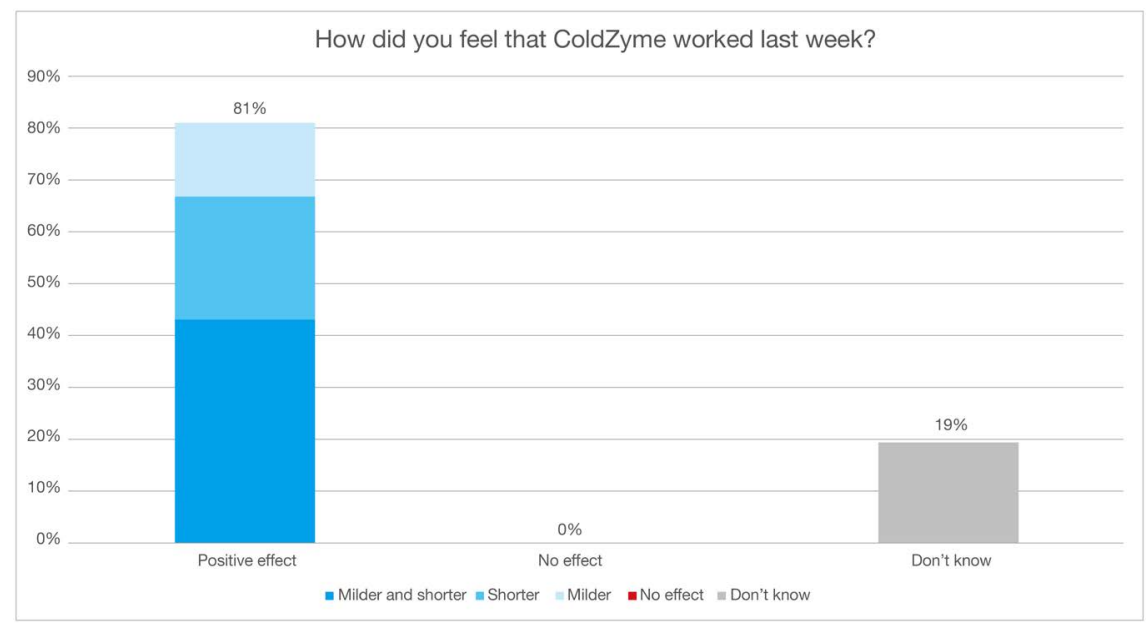

Figure 1. Answers to the question "How did you feel that ColdZyme worked last week?"

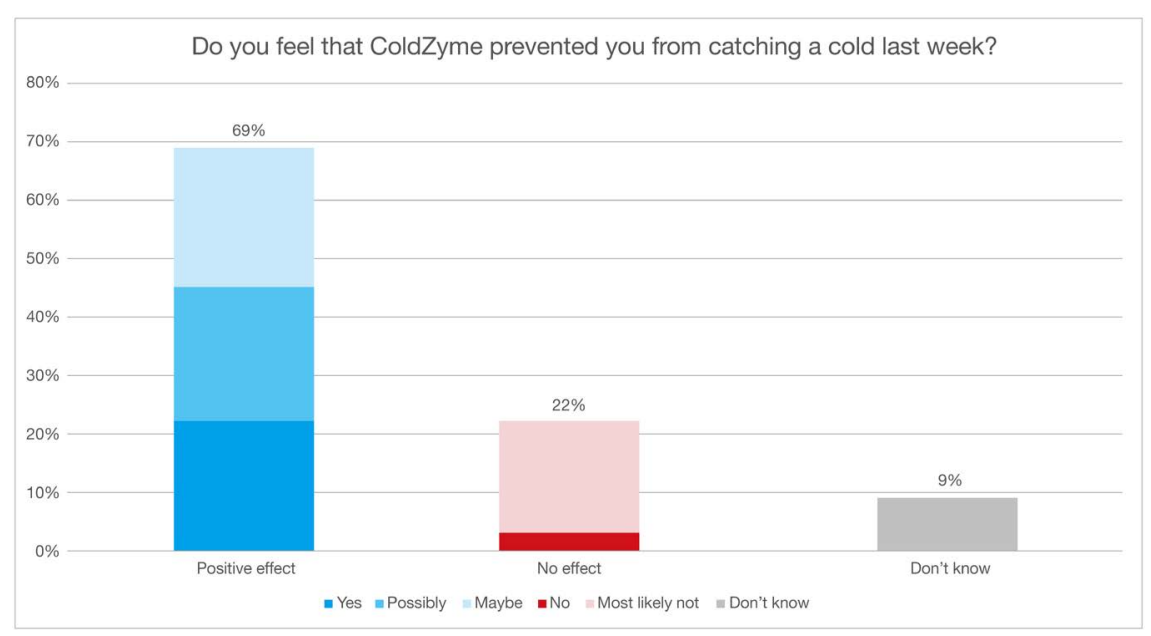

Figure 2. Answer to the question "Do you feel that ColdZyme prevented you from catching a cold last week?" 


\section{Discussion}

The high response rate of at least $77 \%$ throughout the evaluation period is most likely the result of the participants being motivated to evaluate ColdZyme, as they had expressed an interest in the product. This group, athletes, are used to keeping training dairies and reporting and evaluating their diet and physical status and symptoms, which might contribute to a higher response rate. If weekly surveys, instead of daily reporting, are to be used in future studies as well, the question "How many days did you have a cold last week" should be replaced by "Which days last week did you have a cold"? This way, the number of incidents and the duration of a separate cold could be calculated with a higher accuracy.

The specific conditions for elite athletes who train hard are linked to a higher risk of being infected by common cold viruses [16] which might be caused by a post-exercise immune function depression after prolonged training. There are several recommendations on how to limit the risk of infection and to limit transmission of infections among athletes, for example to avoid crowded areas, avoid contact with infected persons, to isolate infected team members, get adequate sleep and nutrition etc. [7].

Despite the increased risk in athletes, the number of reported colds in this evaluation is in line with the prevalence for a normal population, which is $2-4$ incidents per subject and year, mostly during the winter [17]. The majority of the participants reported that they felt that ColdZyme prevented them from catching a cold, and for those who did get a cold, the majority reported it to be milder and/or shorter during the study than during prior colds.

Previous studies on the use of ColdZyme by elite athletes demonstrate that ColdZyme use reduced the number of sick days due to common cold, with a corresponding reduction in absence from training by $>50 \%$ among the study participants [18]. These results support previous findings from a double-blind, placebo-controlled study, where subjects treated with ColdZyme displayed significantly decreased viral load and fewer days with common cold symptoms [10]. In the previously referred study [18] athletes who had less than 2 sick days during the preceding months did seem to be less prone to catch a cold during the study period. However, those individuals that reported more than two sick days during the three months preceding the actual survey, seemed to benefit more from using ColdZyme [18]. Observational studies, like the above, allow the assessment of benefit in real-life settings, but due to the open label un-blinded design without placebo they are more exposed to bias, and the results should therefore be considered as preliminary. The current evaluation was performed on naturally occurring colds in a defined sub-group of subjects, i.e. athletes, to mimic a real-life setting, although the lack of a comparator group is a weakness of the study.

\section{Conclusion}

Satisfaction was high in both the group of participants who did experience a cold 
and the group who did not experience a cold. $81 \%$ of the reported colds were experienced as milder and/or shorter than usual and $69 \%$ of the participants who did not have a cold reported that they experienced that ColdZyme had prevented or might have prevented them from catching a cold in the previous week. Only $12.5 \%$ of the participants with a cold avoided physical exercise during their cold. This indicates that the use of ColdZyme may be an easy and practical method for competitive athletes to alleviate and prevent or reduce infections of a naturally acquired common cold virus and corresponding unwanted absence from training and competition, if used at an early stage.

\section{Acknowledgements}

The authors would like to thank Elisabeth Sthengel for her contribution to this evaluation.

\section{References}

[1] Spence, L., Brown W., Pyne, D., Nissen, M., Sloots, T., Mccormack, J., Locke, S. and A Fricker, P. (2007) Incidence, Etiology, and Symptomatology of Upper Respiratory Illness in Elite Athletes. Medicine and Science in Sports and Exercise, 39, 577-586. https://doi.org/10.1249/mss.0b013e31802e851a

[2] Gleeson, M. and Pyne, D. (2016) Respiratory Inflammation and Infections in High-Performance Athletes. Immunology and Cell Biology, 94, 124-131.

https://doi.org/10.1038/icb.2015.100

[3] Walsh, N. and Oliver, S. (2016) Exercise, Immune Function and Respiratory Infection: An Update on the Influence of Training and Environmental Stress. Immunology and Cell Biology, 94, 132-139. https://doi.org/10.1038/icb.2015.99

[4] Nieman, D. (1994) Exercise, Infection, and Immunity. International Journal of Sports Medicine, 15, S131-S141. https://doi.org/10.1055/s-2007-1021128

[5] Gleeson, M. (2007) Immune Function in Sport and Exercise. Journal of Applied Physiology, 103, 693-699. https://doi.org/10.1152/japplphysiol.00008.2007

[6] Schwellnus, M., et al. (2016) How Much Is Too Much? (Part 2) International Olympic Committee Consensus Statement on Load in Sport and Risk of Illness. British Journal of Sports Medicine, 50, 1043-1052. https://doi.org/10.1136/bjsports-2016-096572

[7] Alonso, J., et al. (2012) Determination of Future Prevention Strategies in Elite Track and Field: Analysis of Daegu 2011 IAAF Championships Injuries and Illnesses Surveillance. British Journal of Sports Medicine, 46, 505-514.

https://doi.org/10.1136/bjsports-2012-091008

[8] Kemmerer, T.P., Cetron, M., Harper, L. and Kozarsky, P.E. (1998) Health Problems of Corporate Travelers: Risk Factors and Management. Journal of Travel Medicine, 5, 184-187. https://doi.org/10.1111/j.1708-8305.1998.tb00504.x

[9] Vareille, M., Kieninger, E. and Edwards, M.R. (2011) The Airway Epithelium: Soldier in the Fight against Respiratory virusEs. Clinical Microbiology Reviews, 24, 210-229. https://doi.org/10.1128/CMR.00014-10

[10] Clarsund, M., Fornbacke, M., Uller, L., Johnston, S. and Emanuelsson, C. (2017) A Randomized, Double-Blind, Placebo-Controlled Pilot Clinical Study on ColdZyme ${ }^{\bullet}$ Mouth Spray against Rhinovirus-Induced Common Cold. Open Journal of Respiratory Diseases, 7, 125-135. https://doi.org/10.4236/ojrd.2017.74013 
[11] Rousse, M., Cucuat, N., Janicot, C. and Shrivastava, R. (2014) Innovative Scientific Concept of Topical Virus Glycoprotein Inhibitors Incorporated in Hyperosmotic Glycerol Revolutionizes Future Prospects in the Treatment of Viral and Bacterial Throat Infections. International Journal of Pharmaceutical Sciences and Drug Research, 6, 1-11

[12] Stefansson, B., Gudmundsdottir, A. and Clarsund, M. (2017) A Medical Device Forming a Protective Barrier That Deactivates Four Major Common Cold Viruses. Virology Research Reviews, 5.

[13] Jackson, G., Dowling, H., Spiesman, I. and Boand A. (1958) Transmission of the Common Cold to Volunteers under Controlled Conditions. AMA Archives of Internal Medicine, 101, 267-278.

https://doi.org/10.1001/archinte.1958.00260140099015

[14] Asch, D., Jedrziewski, K. and Christakis, N. (1997) Response Rates to Mail Surveys Published in Medical Journals. Journal of Clinical Epidemiology, 50, 1129-1136. https://doi.org/10.1016/S0895-4356(97)00126-1

[15] Allan, G.M. and Arroll, B. (2014) Prevention and Treatment of the Common Cold: Making Sense of the Evidence. CMAJ: Canadian Medical Association Journal, 186, 190-199. https://doi.org/10.1503/cmaj.121442

[16] Moreira, A., Delgado, L., Moreira, P. and Haahtela, T. (2009) Does Exercise Increase the Risk of Upper Respiratory Tract Infections? British Medical Bulletin, 90, 111-131. https://doi.org/10.1093/bmb/ldp010

[17] Informed Health Online, Common Cold Overview. PubMed Health. https://www.ncbi.nlm.nih.gov/pubmedhealth/PMH0072727/\#i2642.sources

[18] Clarsund, M. (2017) Evaluation of ColdZyme Mouth Spray for the Protection against Common Cold in Elite Athletes to Reduce Unwanted Absence from Training and Competition. Open Journal of Respiratory Diseases, 7, 103.

https://doi.org/10.4236/ojrd.2017.73010 